\title{
Phragmites australis Associates with Belowground Fungal Communities Characterized by High Diversity and Pathogen Abundance
}

\author{
Carolyn S. Schroeder ${ }^{1, *}$, Susannah Halbrook ${ }^{1}$, Christina Birnbaum ${ }^{1,2,3} \mathbb{C}^{\mathbb{C}}$, Paweł Waryszak ${ }^{1,3} \mathbb{D}^{\mathbb{D}}$, \\ William Wilber ${ }^{1}$ and Emily C. Farrer ${ }^{1}$ (i) \\ 1 Department of Ecology and Evolutionary Biology, Tulane University, New Orleans, LA 70118, USA; \\ shalbroo@tulane.edu (S.H.); wwilber@tulane.edu (W.W.); efarrer@tulane.edu (E.C.F.) \\ 2 School of Science, Applied Chemistry and Environmental Science, RMIT University, Melbourne, VIC 3001, \\ Australia; chbirnbaum@gmail.com \\ 3 School of Life and Environmental Sciences, Centre for Integrative Ecology, Faculty of Science \& Built \\ Environment, Deakin University, 221 Burwood Highway, Burwood, VIC 3125, Australia; \\ pawel.waryszak@gmail.com \\ * Correspondence: cschroeder@tulane.edu
}

Received: 4 August 2020; Accepted: 18 September 2020; Published: 22 September 2020

\begin{abstract}
Microbial symbionts are gaining attention as crucial drivers of invasive species spread and dominance. To date, much research has quantified the net effects of plant-microbe interactions on the relative success of native and invasive species. However, little is known about how the structure (composition and diversity) of microbial symbionts can differ among native and invasive species, or vary across the invasive landscape. Here, we explore the structure of endosphere and soil fungal communities associated with a monoculture-forming widespread invader, Phragmites australis, and co-occurring native species. Using field survey data from marshes in coastal Louisiana, we tested three hypotheses: (1) Phragmites australis root and soil fungal communities differ from that of co-occurring natives, (2) Phragmites australis monocultures harbor distinct fungal communities at the expanding edge compared to the monodominant center, and (3) proximity to the P. australis invading front alters native root endosphere and soil fungal community structure. We found that $P$. australis cultivates root and soil fungal communities with higher richness, diversity, and pathogen abundances compared to native species. While $P$. australis was found to have higher endosphere pathogen abundances at its expanding edge compared to the monodominant center, we found no evidence of compositional changes or pathogen spillover in native species in close proximity to the invasion front. This work suggests that field measurements of fungal endosphere communities in native and invasive plants are useful to help understand (or rule out) mechanisms of invasion.
\end{abstract}

Keywords: invasion; microbes; endosphere; endophytes; pathogens; fungi; Phragmites; haplotype I; gulf haplotype; coastal marsh

\section{Introduction}

Globally, plant invasions reduce biodiversity and alter ecosystem function. Thus, the investigation of patterns and processes underlying invasion is a central theme in ecological research. Plant-microbe interactions are increasingly recognized as key drivers of invasion success [1,2]. Plants cultivate two distinct communities of microbial symbionts that may influence their expansion: the soil community (pool of microbes in the surrounding soil) and the endosphere (microbes within plant tissues) [3]. To date, most research on microbially mediated invasion mechanisms has focused on plant-soil interactions [4-6]. The plant-soil feedback framework posits that plants cultivate soil 
microbes in a species-specific fashion [7], which in turn influences plant growth and plant-plant competition [8] through a variety of possible mechanisms, including release from natural enemies [9], novel weapons [10], biotic resistance [11], accumulation of local soil pathogens [12], and disruption of mutualistic associations [13].

Despite this depth of knowledge on the role of plant-soil interactions in promoting invasion, little is known about how plant microbiome compartments (i.e., the endosphere and soil community) are structured during the process of invasion. Traditionally, plant-soil feedback research regarding invasion has quantified net effects of soil and endosphere communities on native and invasive performance $[7,14,15]$. However, a few studies have characterized the composition of invasive and native microbiomes in situ. Rodriguez-Caballero et al. [16] found that invasive Nicotiana glauca cultivated a specific rhizosphere microbial community with distinct metabolic functions. Gomes et al. [17] observed that three invasive tree species increase richness, but did not alter composition, of arbuscular mycorrhizal fungi. Additional previous work characterizing the soil and endosphere composition of invasive plant species [18-20] and among native and invasive genotypes [21-23] has shown that understanding patterns of microbial composition (i.e., putative pathogen abundance) in the field can point to relevant microbial invasion mechanisms, such as enemy release or pathogen accumulation [23-25].

While invasive and native plants have been shown to have different microbiomes [21-23,25], little is known about how an invader's microbiome varies across an invasion landscape. Many invasive species expand in an invading front; thus, individuals of the invading population interact with distinct plant assemblages at different stages of invasion. In the early stages of invasion, the invasive species is rare and surrounded by a diverse community of heterospecifics, while as the invasion progresses, the invader is surrounded by conspecifics. These very different biotic contexts likely influence the invasive species' endosphere and surrounding soil communities [25]. Comparing microbial communities at the invader's expanding edge with its monodominant core allows us to identify groups of taxa that potentially influence spread at early stages of invasion.

An expanding invasive front also creates distinct community contexts for the resident native species. It is well established that invasive species can influence the composition of soil biota, which can hinder the growth of native plants $[8,13]$. However, the degree to which an invader's presence actually alters native microbiomes has not been quantified. Investigating how the microbiomes of native plants are influenced by their proximity to the invading front can inform us about the likelihood of pathogen spillover or other microbial mechanisms contributing to native decline and invasive spread.

Here, we specifically investigate fungal root endosphere and soil assemblages of an invasive wetland grass, Phragmites australis (Cav.) Trin. ex Steudel (common reed), and neighboring native species. Phragmites australis is considered a model invasive species that aggressively spreads in both inland and coastal systems worldwide [26-28]. The majority of research regarding P. australis invasion success examines physiological traits [29-31], but recent studies have explored the potential role that microbial communities play in P. australis invasion. Previous work has shown that P. australis associates with a wide range of fungal endophytes [18,22,32], the composition of which can vary across environmental gradients $[19,21]$. Despite a growing body of literature on P. australis fungal symbionts, little is known about how $P$. australis' endosphere and soil communities influence its invasion dynamics.

We focus on P. australis invasion in Gulf Coast marshes, which harbor a diverse and understudied array of P. australis haplotypes [33,34]. We examine fungi associated with the most abundant haplotype in the region, haplotype I, or the "Gulf haplotype" [34]. A hybrid between P. australis and P. mauritianus, haplotype I is either an introduction to North America from Africa, or possibly of North America origin [34,35]. Haplotype I is spreading in the Gulf Coast [36], where it reduces plant diversity and alters soil microbial composition [37]. For these reasons, we refer to haplotype I as an invasive species but recognize the need for further research into its historical range and natural history.

Here, we examine field patterns in soil and root endosphere community structure (composition and diversity) of fungi associated with P. australis and native plants using data from six invaded marsh 
sites in coastal Louisiana. We test three hypotheses: (1) Phragmites australis root and soil fungal communities will differ from that of co-occurring natives, (2) Phragmites australis roots will harbor distinct fungal microbial community structure at the expanding edge compared to the monodominant center, and (3) proximity to the P. australis invading front will alter native root and soil fungal structure. For clarity, we refer to the P. australis monoculture and native community as "community types", whereas we refer to differences in plant composition ("center" and "edge") within a P. australis monoculture and the native community as "biotic contexts". For each of these community types and biotic context comparisons, we assess differences in root and soil fungal composition, richness, diversity, and putative plant pathogen abundances.

\section{Materials and Methods}

\subsection{Study Sites}

Samples were collected from six freshwater to brackish marsh sites in southeast Louisiana (see Supplementary Figure S1). At each site, 21 permanent $1 \mathrm{~m}$ by $1 \mathrm{~m}$ plots were established in three transects: monoculture center, edge, and native center, each with seven plots spaced roughly $10 \mathrm{~m}$ apart. The monoculture center transect plots were placed through the center of a P. australis monoculture stand. The native center plots ran parallel to, but outside of, the P. australis stand, roughly $10 \mathrm{~m}$ from the edge of the stand, and contain only native plants representing the native marsh community. The edge plots ran along the edge of the P. australis stand, capturing the interface of the native community and the invading P. australis front. Plots in each transect were spaced $10 \mathrm{~m}$ apart from the neighboring plots within the same transect. The distance between the monoculture center and edge transect depended on the size of the P. australis stand, ranging from 5-10 m apart.

\subsection{Sample Collection}

Samples were collected in October and November 2017, during the time of year in which the majority of local native plant species are identifiable by flowers or fruits. In the center of each plot, soils samples were collected with a sterilized soil corer $(10 \mathrm{~cm}$ depth and $5 \mathrm{~cm}$ diameter), homogenized, and stored in cryovial sample tubes. Root samples were collected from one individual of the dominant plant species in P. australis and native plots, and both P. australis and the dominant native in the edge plots. In native plots, we collected samples from a total of 8 species: Spartina patens, Eleocharis sp., Schoenoplectus americanus, Polygonum punctatum, Juncus roemarinus, Paspalum dissectum, Sacciolepis striata, and Ipomoea saggitata. See Supplementary Table S2 for information about the number of species collected from each transect at each site. In the field, fine roots were randomly cut from 5 different root sections in each individual plant into 1-2 cm segments and rinsed in a sterile water bath. From this sterile water bath, a random selection of root segments were collected for processing. Roots were then surfaced sterilized by submerging segments into $70 \%$ ethanol, $3 \%$ bleach, and autoclaved, deionized water for $1 \mathrm{~min}$ each. Soil and root samples were placed directly into a liquid nitrogen container and transferred to $\mathrm{a}-80^{\circ} \mathrm{C}$ freezer upon returning to the lab. At each plot, soil porewater was collected at a depth of $15 \mathrm{~cm}$ using soil sippers (a plastic tube with perforations in one end attached to a syringe). Soil sippers can be inserted into the soil to collect porewater specifically and avoid surface water, allowing for a more accurate measure of soil parameters. Soil porewater salinity and $\mathrm{pH}$ were measured with a probe (YSI). Bulk soil samples were sent to Louisiana State University's Agricultural Center (Baton Rouge, LA, USA) for analysis, including $\mathrm{pH}$, phosphorus, organic nitrogen, potassium, and carbon content.

\subsection{Molecular Methods}

DNA was extracted from the soil samples with Qiagen DNeasy PowerSoil Kit and root samples with DNeasy PowerPlant Pro Kit (Qiagen Inc.) following the manufacturer's protocol. Extractions were standardized to $10 \mu \mathrm{g} / \mu \mathrm{L}$ and amplified in duplicate using the primers F-ITS1F and ITS2 to sequence the fungal ITS region. Duplicate amplicons were pooled and indexed. Negative controls were 
also amplified and sequenced. All samples were visualized with gel electrophoresis after each PCR to confirm amplification and identify potential contamination. Soil samples were purified with Sequalprep (Invitrogen Inc.,USA) and root samples were purified with AMPure beads (Beckman Coulter, Indianapolis, IN, USA). Samples were pooled to create three libraries and were sequenced on three lanes of an Illumina Miseq v3 (300 bp PE) by Duke Sequencing Core (Duke University, Durham, NC, USA).

After receiving demultiplexed sequences, the DADA2 pipeline was used for filtering, dereplication, chimera identification, merging pair-end reads, and taxonomic assignment [38]. We rarefied samples to 5500 reads per sample. We checked for and removed fungal contaminants using the decontam function in the decontam R package, using the "prevalence" option.

Putative functional categories were assigned to each amplicon sequence variant (ASV) using the FunGUILD database [39]. FunGUILD classifies fungal ASV's by trophic mode and functional guilds, which are assigned at the fungal genus level. Plant pathogen abundance for each sample was calculated by summing relative abundances of ASVs classified as plant pathogens within each sample. For this, we included fungal taxa classified as plant pathogens, even if they were assigned multiple functional classifications. If no functional grouping could be identified for a particular ASV, this ASV was excluded from functional analyses. Thus, "pathogen abundance" represents the proportion of sequences per sample that were identified as pathogens.

Hill's diversity indices, including richness, the antilogarithm of Shannon's entropy index (hereafter referred to as 'antilogarithm Shannon'), and the inverse of Simpson's concentration index (hereafter referred to as 'inverse Simpson') [40] were calculated for each root and soil fungal sample using the hilldiv package in R [41]. Hill numbers are recommended for characterizing the diversity of samples in molecular datasets, partially because they can be intuitively interpreted as the "effective number" of ASVs [42]. Additionally, Hill's series of diversity indices represent a range of sensitivity toward rare and abundant ASVs [40,41].

\subsection{Statistical Analysis}

We tested our three hypotheses with a combination of constrained ordinations and linear models that fall under three primary plant community comparisons: (1) monoculture vs. native community types, (2) center vs. edge biotic contexts within a P. australis monoculture, and (3) center vs. edge biotic contexts within a native community. For each of these primary comparisons, we contrasted root and soil fungal composition, diversity indices, and putative plant pathogen abundances. All analyses were conducted using R statistical software [43]. We performed constrained ordinations (distance-based redundancy analysis (dbRDA)) to assess differences in fungal composition using the capscale() function in the package vegan [44]. In each dbRDA model, site was included as a condition term to remove variation due to differences among sites. Permutation tests (PERMANOVAs) were done using the anova() function with the "by margin" option to assess the marginal significance of explanatory variables. Mixed effect linear models were used to analyze the effect of community type or biotic context on diversity indices and putative plant pathogen abundances. Linear models were fit using the package nlme [45] and each included site as a random effect. Species identity was not included in models because some of our species were only sampled once or twice (see Table S2), making some of our species groups too small to be used as a random effect category. The significance of effects of individual variables in linear models was assessed using type III ANOVA.

The different plots sampled (monoculture, edge, and native) likely differ in abiotic characteristics and are also arrayed in space (with some plots closer to one another than others), which can drive differences in fungal composition. In order to remove the effect of abiotic factors and distance on fungal composition so that we tease apart the effect of community type and biotic context per se, for each dbRDA and linear model, we performed backwards model selection using community type (or biotic context), abiotic variables (including $\mathrm{pH}$, porewater salinity, and carbon, phosphorus and nitrogen content), and their interactions as explanatory variables. All abiotic variable values were 
rescaled (normalized) between 0 and 1 before applying to models so that all variables would have the same ranges and model coefficients would be the same order of magnitude. For linear models, backwards model selection was performed following methods in Zuur et al. [46]. We started with a model including all abiotic variables as fixed effects. During this selection process, models were fit using maximum likelihood. Non-significant abiotic variables were removed from models in a stepwise fashion, starting with fixed effects with the highest $p$-values. We compared models using AIC values to ensure that removing each variable improved model fit. When removing fixed effects no longer improved model fit, we included all two-way interactions between the focal fixed effect (community type or biotic context), to test whether abiotic variables alter the effect of the focal fixed effect on the response variables. Final models were fit using restricted maximum likelihood [46]. For dbRDA models, backwards model selection was performed by hand in a similar stepwise fashion, and abiotic variables were removed only if model fit was improved. In each dbRDA model, distance was modeled using the first axis of principal coordinates of neighborhood matrix (PCNM) analyses for each site [47]. PCNM output values from each site were concatenated for use as a condition term (similar to a random effect). For each linear model, exponential spatial correlation structure was included using the corExp function in the package nlme if it improved model fit according to AIC values [45]. The explanatory variables included after model selection for each model are reported in Supplementary Table S1.

Samples from each of the six sites were used for the three primary plant community comparisons. For the "community type" comparisons (hypothesis 1) we used a total of 168 root samples (14 P. australis and 14 native at each of 6 sites) and 84 soil samples (14 plots at each of 6 sites). To analyze root endosphere differences between plants in the monoculture vs. native community types, we used P. australis root samples (from both monoculture and edge transects) and native plant root samples (from both the native and edge transects). Soil community differences between plant community types were analyzed using samples from the monoculture transect and the native community transect. For each "biotic context" comparison, a total of 84 samples were used (14 plots at each of 6 sites). Divergence of root and soil fungal communities between biotic contexts ("center" and "edge") within monocultures (hypothesis 2) was analyzed using P. australis root samples and soil samples from the monoculture and edge transects. Differences in root and soil composition between the native community center vs. edge (hypothesis 3 ) were analyzed using native root samples and soil samples from the native and edge transects.

To visualize differences in root microbial community composition, we created constrained dbRDA ordination plots using ggplot2 [48] and phlyoseq packages [49]. Bar plots were created using ggplot2. To visualize overall differences between diversity indices and plant pathogen abundances between community types and biotic contexts (while including random effects and additional fixed effects), we calculated estimated marginal means and standard errors across all six sites using the emmeans package in R [50]. We identified the five most abundant individual ASVs classified as plant pathogens for each community type by calculating the mean abundance for each ASV and ranking them by highest mean abundance.

\section{Results}

\subsection{Do P. australis Monoculture Root and Soil Fungal Communities Differ from That of the Neighboring Native Community?}

Root endosphere composition strongly differed between P. australis and the native community (Figure 1A). Richness, antilogarithm Shannon, and inverse Simpson were higher in P. australis roots than in native roots (Figure 2A-C). Mean putative pathogen abundance was 3.3 times higher in $P$. australis roots than in native roots (Figure 2D), and nitrogen independently increased pathogen abundance (Supplementary Table S1). A total of 150 fungal genera in P. australis roots were classified as pathogens, compared to 139 in native roots. The most abundant putative pathogen in P. australis roots, Magnaporthe, a fungal genus that contains five widespread plant pathogens, including rice blast fungus [51], accounted for 6.8\% mean relative abundance (MRA) across the 84 P. australis root 
samples. Other abundant putative pathogens in P. australis roots included Giberella (2.5\% MRA), Marasmius (1\% MRA), Curvularia (1\% MRA), and Fusarium (1\% MRA). The same plant pathogen taxa were most abundant in native roots, but mean relative abundances were lower than in $P$. australis roots: Magnaporthe (1.4\% MRA), Curvularia (1\% MRA), Marasmius (0.7\% MRA), Fusarium (0.6\% MRA), and Giberella (0.5\% MRA).

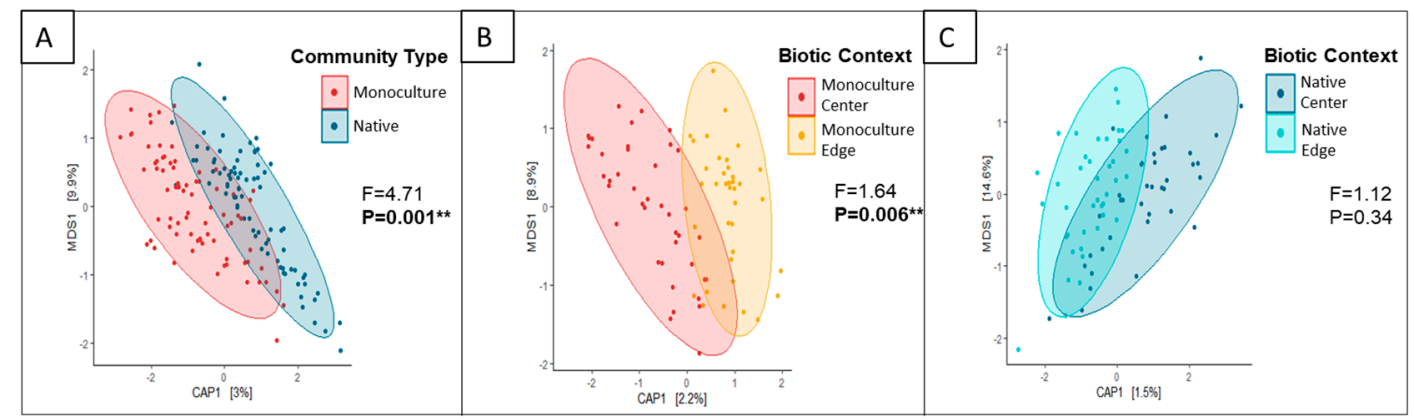

Figure 1. Constrained ordinations showing the effect of community type and biotic context on fungal root composition. Each point represents the root endosphere of an individual plant. Ellipses represent a $95 \%$ confident interval for each group. Endosphere composition differed significantly between the monoculture and native community types (A). Endosphere composition also differed between the center and edge biotic contexts within the monoculture community (B). There was no difference in endosphere composition between the center and edge biotic contexts within the native community (C). $P$-values less than 0.1 are highlighted in bold and labeled with the following notation: $+p<0.1$, ${ }^{*} p<0.05,{ }^{* *} p<0.01,{ }^{* * *} p<0.001$.

Soil fungal composition also differed between the P. australis monoculture and native community (Supplementary Figure S2A). Soil $\mathrm{pH}$ had a significant but weaker impact on fungal composition (Supplementary Table S1). Phragmites australis monoculture soils had slightly higher soil fungal richness antilogarithm Shannon, and inverse Simpson than native soils, similar to the root endosphere patterns (Figure 2E-G). Nitrogen increased both diversity and richness independently of community type (Supplementary Table S1). Also similar to the endophyte results, pathogen abundance was 1.8 times higher in P. australis monoculture soils than in native soils (Figure $2 \mathrm{H}$ ) and soil nitrogen increased root pathogen abundance (Supplementary Table S1). Total pathogen abundances were lower in soil samples than in root samples (Figure 2D,H). In P. australis monoculture soils, the most abundant taxa identified as plant pathogens include Curvularia (1.3\% MRA), Magnaporthe (0.8\% MRA), Fusarium (0.6\% MRA), Chalara (0.3\% MRA), and Giberella (0.3\% MRA). In native community soils, the most abundant putative plant pathogens were Curvularia (0.5\% MRA), Fusarium (0.3\% MRA), Marasmius (0.3\% MRA), Veronaea (0.2\% MRA), and Magnaporthe (0.1\% MRA).

\subsection{Does P. australis Harbor Distinct Fungal Communities at Its Expanding Edge Compared to Its Monodominant Center?}

Phragmites australis endosphere fungal composition differed between the center of the monoculture and the edge (Figure 1B). Biotic context had no effect on endosphere richness, antilogarithm Shannon, or inverse Simpson (Figure 3A,B). Pathogen abundances were 1.4 times higher in P. australis roots at the edge of the stand compared to roots in the monodominant center (Figure 3D). Similar to patterns reported in the community type comparisons above, soil nitrogen content also significantly increased pathogen abundance independent of biotic context (Supplementary Table S1). 


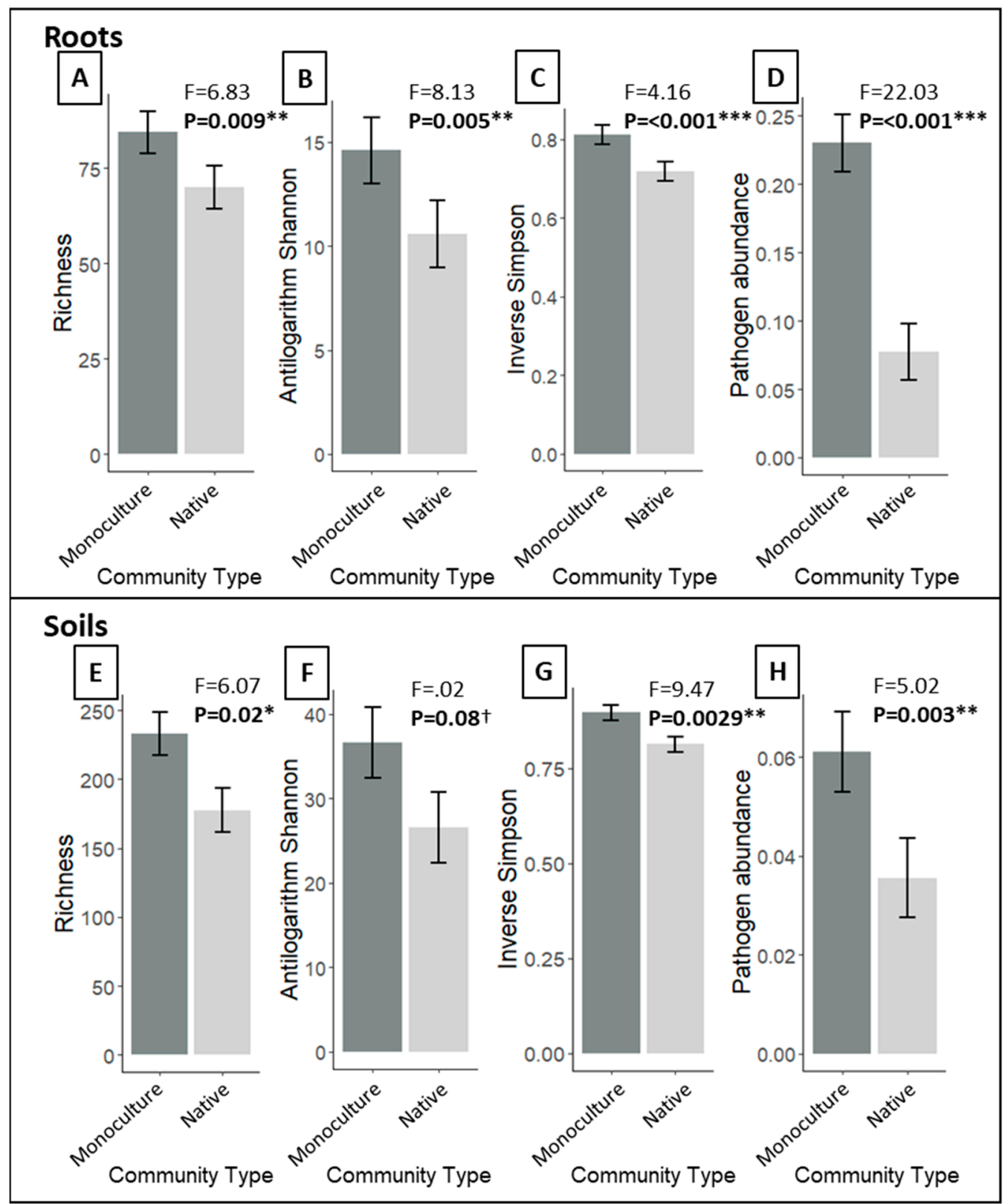

Figure 2. Fungal richness, antilogarithm of Shannon's entropy index, inverse of Simpson's concentration index, and total putative plant pathogen abundance in P. australis monoculture (dark grey) and native (light grey) community types. (A-D) display estimated marginal means and standard errors of root fungal endosphere responses to community type. (E-H) show estimated marginal means and standard errors of soil fungal community responses to community type. $P$-values less than 0.1 are highlighted in bold and labeled with the following notation: $+p<0.1,{ }^{*} p<0.05,{ }^{* *} p<0.01,{ }^{* * *} p<0.001$.

Soil fungal composition within the P. australis stand was influenced by biotic context and soil $\mathrm{pH}$ (Supplementary Table S1, Supplementary Figure S2B). There was no difference in soil richness, antilogarithm Shannon, inverse Simpson, or pathogen abundance between biotic contexts (Figure 3E-H), but soil nitrogen and $\mathrm{pH}$ increased soil richness and soil nitrogen increased inverse Simpson diversity (Supplementary Table S1). 


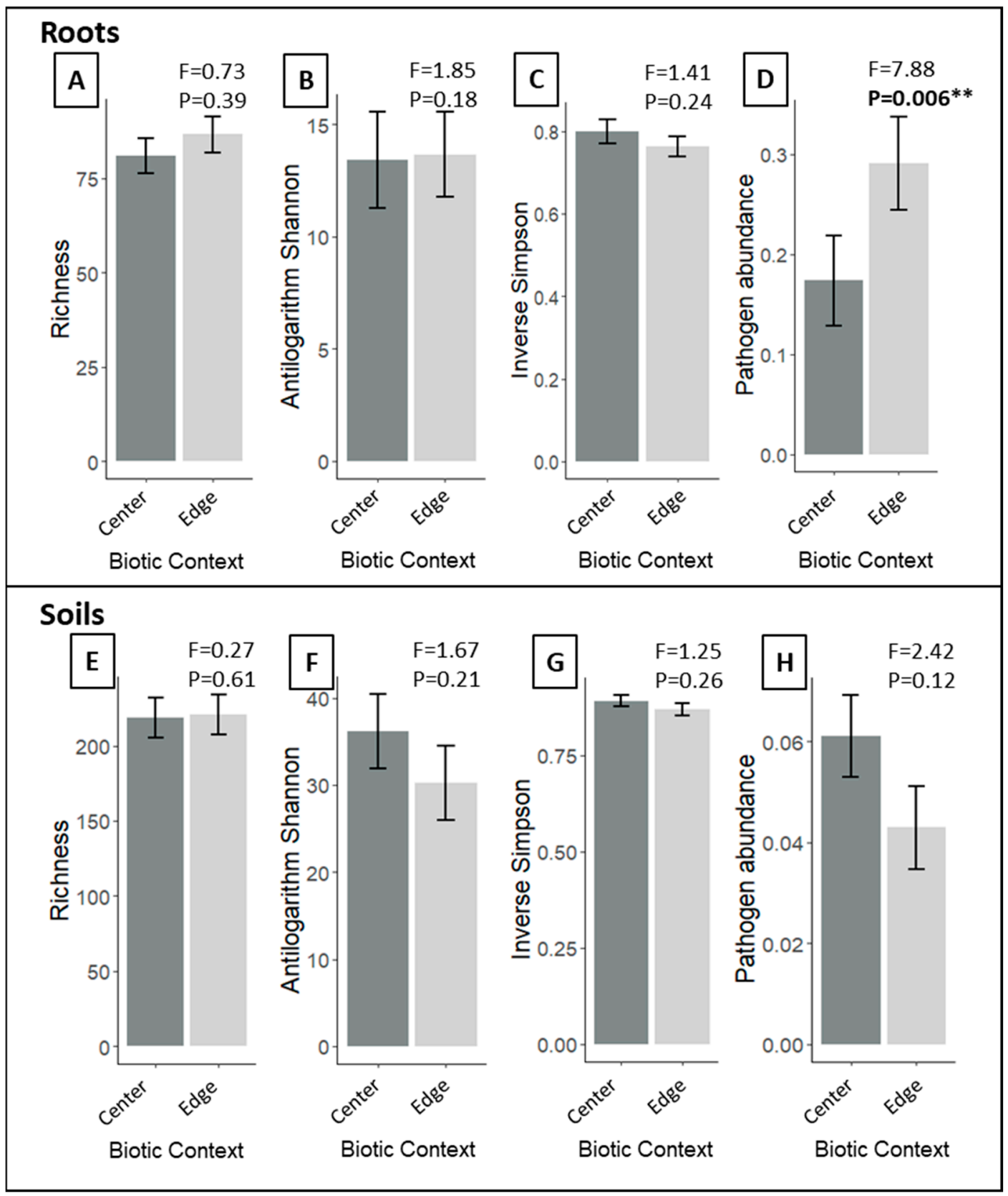

Figure 3. Fungal richness, antilogarithm of Shannon's entropy index, inverse of Simpson's concentration index, and total putative plant pathogen abundance in center (dark grey) and edge (light grey) biotic contexts within Phragmites australis monocultures. (A-D) display estimated marginal means and standard errors of root fungal endosphere responses to biotic context. (E-H) show estimated marginal means and standard errors of soil fungal community responses to biotic context. $P$-values less than 0.1 are highlighted in bold and labeled with the following notation: $+p<0.1{ }^{*} p<0.05,{ }^{* *} p<0.01$, *** $p<0.001$.

\subsection{Does Proximity to the P. australis Invasion Front Alter Native Root and Soil Fungal Community} Composition, Diversity or Pathogen abundances?

Proximity to $P$. australis did not affect native root endosphere composition (Figure 1C). Instead, soil $\mathrm{pH}$ was a driver of root composition (Supplementary Table S1). Native root richness and antilogarithm Shannon were higher in plants adjacent to the P. australis monoculture edge (Figure 4A,B). Native root inverse Simpson and pathogen abundance were not influenced by biotic context (Figure 4C,D). 


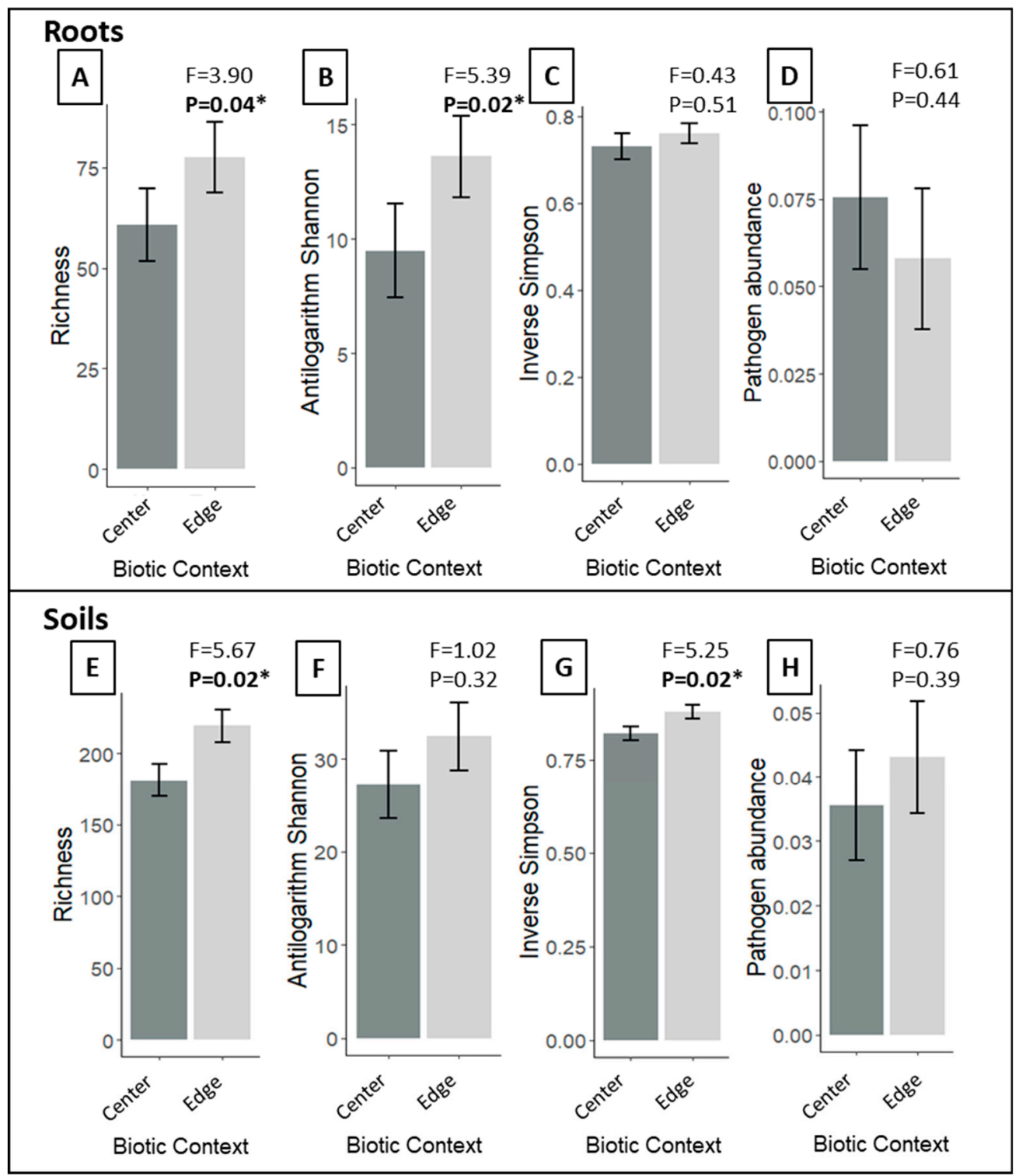

Figure 4. Fungal richness, antilogarithm of Shannon's entropy index, inverse of Simpson's concentration index, and total putative plant pathogen abundance in center (dark grey) and edge (light grey) biotic contexts within native communities. (A-D) display estimated marginal means and standard errors of root fungal endosphere responses to biotic context. $(\mathbf{E}-\mathbf{H})$ show estimated marginal means and standard errors of soil fungal community responses to biotic context. $P$-values less than 0.1 are highlighted in bold and labeled with the following notation: $+p<0.1,{ }^{*} p<0.05,{ }^{* *} p<0.01,{ }^{* * *} p<0.001$.

Differences in biotic context within the native community did not affect soil fungal composition (Supplementary Figure S2C). Instead, soil pH was a primary driver of composition (Supplementary Table S1). Soil richness and inverse Simpson was slightly higher in edge plots (Figure 4E,G), compared to native plots, but there was no difference in antilogarithm Shannon (Figure $4 \mathrm{~F}$ ) or pathogen abundance (Figure 4H). Salinity decreased fungal richness, regardless of biotic context (Supplementary Table S1).

\section{Discussion}

Invasive monocultures likely transform local pools of plant symbionts and possibly alter the endosphere compositions of nearby native species, but this has rarely been tested in the field. Here we present evidence that $P$. australis' root endosphere and soil fungal associates indeed differ from that of native species and house endosphere assemblages with higher richness, diversity, and putative 
plant pathogen abundances. At the native community boundary, $P$. australis roots contain distinct fungal compositions with higher pathogen loads. Despite this, we do not find evidence that native endosphere composition or pathogen abundances are influenced by proximity to the invasion front. However, we do find that native root endosphere richness and diversity increase at the P. australis expanding edge. Below, we discuss how these results shape our understanding of $P$. australis' fungal microbiome, its impact on neighboring native plants, and the process of invasion.

\subsection{Contrasting Fungal Composition, Richness, and Diversity in P. australis Monocultures and Native Communities}

We find strong compositional differences in P. australis and native symbiont communities, which aligns with previous findings that host plant species identity is a crucial determinant of both soil [52] and endosphere composition [53,54]. Plant species cultivate distinct soil communities using a number of mechanisms, including the production of root exudates that preferentially amplify or exclude particular fungal taxa [55]. Individual plant species then act as a biotic filter by cultivating a subset of the available microbial pool, resulting in an endosphere community distinct from the background soil. While some endophytic colonization may be random, biotic filtering mechanisms allow different species grown in the same soil to assemble distinct endosphere compositions [56,57].

To date it is unclear whether the diversity of microbial associates of native and invasive plants differs in a systematic way. Si et al. [58] report that soil fungal Shannon diversity increased with the density of the invasive plant Wedelia trilobata. However, Lankau et al. [59] observes that soil community richness declines in the initial stages of Alliaria petiolata invasion, but recovers overtime. Bickford et al. [22] found no differences in root fungal endosphere richness or diversity among invasive and native $P$. australis lineages. Here, we find that $P$. australis fosters more diverse root and soil fungal communities compared to native species. Bowen et al. [23] proposed that release from natural enemies allows invasive P. australis to devote fewer resources towards pathogen defense mechanisms. We speculate that this reduction in biotic filtering mechanisms may allow invasive lineages of $P$. australis to associate with a wider range of fungal taxa. Further examination of other invasive-native systems, as well as biotic filtering mechanisms in invasive plants, could provide more generalized insight into why invaders cultivate more or less diverse endophytic and soil fungi, compared to native species.

\subsection{Phragmites australis Harbors Higher Putative Pathogen Abundances than Co-Occuring Native Species}

Our observation that putative pathogen abundances are higher in P. australis soils is congruous with previous work describing that invaders accumulate local soil pathogens $[12,60,61]$. Accumulation of local pathogens in invaded soils has been well-documented; however, whether or not invasive species amplify plant pathogens within their tissues has received less attention. It has been shown that invasive Ageratina adenophora amplifies local pathogens in its leaf tissues asymptomatically [62]. Previous culture-based work found that fungal leaf pathogen abundances were higher in native and European P. australis lineages than in Gulf and Delta lineages [21], while metagenomic work has shown that there is no difference in pathogen abundance between native and invasive lineages [22]. To our knowledge, this is the first study to report that putative pathogen abundances are higher in the internal tissues of an invasive species compared to co-occurring native species. This suggests that fungal pathogen accrual within P. australis' endosphere, in addition to accrual within its soils, is an important pathway for pathogen accumulation in this system.

We found that $P$. australis amplifies plant pathogens in its tissues and soils, but the effect of this process on the direction of invasion hinges on whether these putative plant pathogens are pathogenic or asymptomatic in P. australis. Invasive species often benefit from enemy release in their invaded range [9], but many invaders accrue local plant pathogens over time [63,64]. If pathogen accrual leads to spillover of pathogens onto native plants with negative consequences for native growth (while invasive plants are relatively asymptomatic), this could result in the exclusion of native species [12,60-62]. Conversely, if local enemies accumulate on invaders and cause relatively more harm to the invader than 
native plants, they can attenuate invasive expansion and generate biotic resistance to invasion $[65,66]$. A number of the most common putative pathogen genera identified in P. australis soils and tissues in this study, including Curvularia, Fusarium, and Giberella, contain species that were found to reduce growth of both European and native P. australis lineages [67]. Soil biota cultivated by invasive lineages of $P$. australis was shown to have a negative impact on itself (and also on co-occurring native species) [68]. This suggests that the local root pathogen accumulation we observe may be detrimental to $P$. australis growth and spread in our system. However, other studies that have found that leaf pathogen damage [21] and root pathogen abundance [22] in the field did not differ between native and invasive $P$. australis lineages suggest that pathogens may not contribute to invasive success or biotic resistance.

\subsection{Phragmites australis Harbors Distinct Soil and Endosphere Fungal Communities at Its Expanding Edge}

A number of papers have investigated variation in invader microbiomes across large geographic areas $[18,21,23]$, but this is the first study to our knowledge that tests whether an invader's microbiome changes at different stages of invasion. We find that root and soil composition differ between the center and edge sections of the $P$. australis invasion front, suggesting that $P$. australis cultivates distinct fungal assemblages at early stages of invasion. Additionally, P. australis harbors higher pathogen abundances at its expanding edge, which indicates that these are local plant pathogens that originate from plants within the native community. The difference in invader endosphere communities at early vs. late stages of invasion may have implications for invader performance during expansion, but experimental work would be necessary to test the implications for invasion.

\subsection{Does Invader Presence Influence Native Endosphere Fungal Composition, Richness, Diversity, or Pathogen Abundance?}

It is well established that invasive plants influence the composition of soil microbes, which can hinder the growth of neighboring species $[7,8,14,61]$. In our system, it has been found that invasive lineages of $P$. australis reduce biomass of a native dominant wetland plant via indirect plant-soil feedbacks involving soil biota [68]. Although it is well-documented that invasive species can alter soil biota, it is unknown whether this translates to changes in endosphere biota. This is a key knowledge gap in invasion ecology, as the endosphere integrates fungal symbionts that are central to host immunity, stress tolerance, and nutrient acquisition $[69,70]$. Previous work demonstrates that an aggressive invader, Bromus tectorum, accumulates a pathogen that infects native seeds [11]. Contrary to our hypotheses, we find that biotic context (native community "edge" and "center") has no impact on root fungal composition within the native community. However, we do find that native root endosphere richness increases at the edge of the P. australis invasion front. Thus, higher native root fungal richness and diversity at the monoculture interface may result from $P$. australis increasing the range of fungi that native roots can draw from.

Despite the fact that $P$. australis harbors high pathogen abundance, we find no evidence of pathogen spillover into native populations. Pathogen 'spillover' or 'spillback' occur when pathogen abundances in one host species are driven not by transmission within that species but by transmission from a reservoir species [64,71]. Evidence that invasive species act as pathogen reservoirs that can impact co-occurring native populations is found in a number of invaded systems $[11,60,61,64]$. These dynamics can result in a reduction in native growth, or in apparent competition, in which both natives and invasive species are negatively impacted by increased pathogen presence $[68,72]$. Given that $P$. australis hosts high pathogen abundances at its expanding edge, we expected that native roots in close proximity to the $P$. australis invasion front would have higher pathogen loads. However, we do not find evidence that proximity to the $P$. australis monoculture edge impacts root or soil pathogen abundance. This suggests that $P$. australis needs to obtain high dominance before it can alter soil pathogen communities and possibly subsequently modify native endosphere communities. While manipulative experiments are 
necessary to test this explicitly, our results challenge the relevance of plant-soil feedbacks in promoting invasion at the expanding edge [66].

\subsection{Limitations}

The primary limitation to this study is that it is a non-manipulative field survey. Here we describe patterns of fungal symbiont community structure among $P$. australis and native species, but we cannot draw definitive conclusions about their impact on the direction of invasion. However, this type of survey is critically important for capturing plant-microbe patterns in field settings. Thus, we call for work combining surveys, manipulative experiments, and metagenomics to tease apart which plant-microbe interactions are relevant and have consequences for invasion.

In this study we only focus on the fungal components of the invaded landscape. We suggest that future work investigate other components of native and invasive symbiont communities, including bacteria. Furthermore, our methods (ITS primers) do not adequately capture arbuscular mycorrhizal fungi diversity and abundances [73], which likely exert strong influences on the outcomes of native and invasive success.

Another important caveat is that the classification of pathogens using the FUNguild database generalizes functional assignment at the genus level. Thus, it is possible that some fungal taxa reported as plant pathogens here may not be pathogenic at all. Furthermore, endosphere fungi often exhibit life-style switching, making it possible for a taxon to be pathogenic in one species, but symbiotic or commensal in another [74]. Regardless, this is the most robust form of functional guild assignment for fungi available to date and it provides useful information about the probability that fungal taxa found in this system are pathogenic. However, future manipulative experiments that test levels of pathogenicity of these taxa in native and invasive plant species are warranted.

\section{Conclusions}

Examining differences in endosphere and soil symbionts of invasive species and co-occurring native species is an important first step in identifying potential microbial mechanisms underlying invasion dynamics. Compared to native species, we find that $P$. australis harbors fungal endosphere communities characterized by high richness, diversity, and pathogen loads. Although P. australis amplifies plant pathogens in its own tissues at the invading front, we find no evidence of pathogen spillover or alteration of endosphere composition in the adjacent native community. Understanding these field patterns enriches our understanding of invasion in general and challenges the relevance of widely accepted invasion mechanisms in P. australis invaded ecosystems.

Supplementary Materials: The following are available online at http://www.mdpi.com/1424-2818/12/9/363/s1, Table S1: Model Results, Table S2: Distribution of Native Species, Figure S1: Map of Site Locations, Figure S2: Soil Constrained Ordination Results.

Author Contributions: Conceptualization, C.S.S., S.H., C.B., P.W., and E.C.F.; methodology, C.S.S., S.H., C.B., and P.W.; formal analysis, C.S.S.; data curation, C.S.S., C.B., P.W., and W.W.; writing-original draft preparation, C.S.S.; writing-review and editing, S.H., E.C.F., P.W., and C.B. All authors have read and agreed to the published version of the manuscript.

Funding: Funding was provided by the Louisiana State Board of Regents grant LEQSF (2017-20)-RD-A-14 to EF.

Acknowledgments: We thank the undergrads who helped in the field and lab: Liana Bethala, Helena Candaele, Isabella Donnell, Nelle Kulick, Helen Weierbach, and Claire Willis. We also thank the many scientists and managers at our field sites who helped with logistics: Julie Whitbeck at Barataria Preserve, Robert Moreau at Turtle Cove, Jessica Dixon at Fontainebleau State Park, Shelley Stiaes at Bayou Sauvage NWR, Daniel Breaux at Big Branch NWR, and Jeffrey Duguay at Pearl River WMA.

Conflicts of Interest: Authors declare no conflict of interest. 


\section{References}

1. Dawson, W.; Schrama, M. Identifying the role of soil microbes in plant invasions. J. Ecol. 2016, 104, 1211-1218. [CrossRef]

2. Van Der Putten, W.H.; Klironomos, J.N.; Wardle, D.A. Microbial ecology of biological invasions. ISME J. 2007, 1, 28-37. [CrossRef] [PubMed]

3. Fitzpatrick, C.R.; Copeland, J.; Wang, P.W.; Guttman, D.S.; Kotanen, P.M.; Johnson, M.T.J. Assembly and ecological function of the root microbiome across angiosperm plant species. Proc. Natl. Acad. Sci. USA 2018, 115, E1157-E1165. [CrossRef]

4. Coats, V.C.; Rumpho, M.E. The rhizosphere microbiota of plant invaders: An overview of recent advances in the microbiomics of invasive plants. Front. Microbiol. 2014, 5, 1-9. [CrossRef] [PubMed]

5. Van Der Putten, W.H. Impacts of soil microbial communities on exotic plant invasions. Trends Ecol. Evol. 2010, 25, 512-519. [CrossRef]

6. Reinhart, K.O.; Callaway, R.M. Soil biota and invasive plants. New Phytol. 2006, 170, 445-457. [CrossRef]

7. Bever, J.D.; Westover, K.M.; Antonovics, J. Incorporating the soil community into plant population dynamics: The utility of the feedback approach. J. Ecol. 1997, 85, 561. [CrossRef]

8. Aschehoug, E.T.; Callaway, R.M.; Newcombe, G.; Tharayil, N.; Chen, S. Fungal endophyte increases the allelopathic effects of an invasive forb. Oecologia 2014, 175, 285-291. [CrossRef]

9. Keane, R. Exotic plant invasions and the enemy release hypothesis. Trends Ecol. Evol. 2002, 17, 164-170. [CrossRef]

10. Callaway, R.M.; Cipollini, D.; Barto, K.; Thelen, G.C.; Hallett, S.G.; Prati, D.; Stinson, K.; Klironomos, J. Novel weapons: Invasive plant suppresses fungal mutualists in america but not in its native Europe. Ecology 2008, 89, 1043-1055. [CrossRef]

11. Beckstead, J.; Parker, I.M. Invasiveness of Ammophila arenaria: Release from soil-borne pathogens? Ecology 2003, 84, 2824-2831. [CrossRef]

12. Eppinga, M.B.; Rietkerk, M.; Dekker, S.C.; De Ruiter, P.C.; Van Der Putten, W.H. Accumulation of local pathogens: A new hypothesis to explain exotic plant invasions. Oikos 2006, 114, 168-176. [CrossRef]

13. Stinson, K.A.; Campbell, S.A.; Powell, J.R.; Wolfe, B.E.; Klironomos, J.N. Invasive plant suppresses the growth of native tree seedlings by disrupting belowground mutualisms. PLoS Biol. 2006, 4, e140. [CrossRef] [PubMed]

14. Suding, K.N.; Harpole, W.S.; Fukami, T.; Kulmatiski, A.; MacDougall, A.S.; Stein, C.; Van Der Putten, W.H. Consequences of plant-soil feedbacks in invasion. J. Ecol. 2013, 101, 298-308. [CrossRef]

15. Klironomos, J.N. Feedback with soil biota contributes to plant rarity and invasiveness in communities. Nature 2002, 417, 67-70. [CrossRef]

16. Rodríguez-Caballero, G.; Roldán, A.; Caravaca, F. Invasive Nicotiana glauca shifts the soil microbial community composition and functioning of harsh and disturbed semiarid Mediterranean environments. Biol. Invasions 2020, 22, 2923-2940. [CrossRef]

17. Gomes, S.I.F.; Merckx, V.S.F.T.; Hynson, N.A. Biological invasions increase the richness of arbuscular mycorrhizal fungi from a Hawaiian subtropical ecosystem. Biol. Invasions 2018, 20, 2421-2437. [CrossRef]

18. Clay, K.; Shearin, Z.R.C.; Bourke, K.A.; Bickford, W.A.; Kowalski, K.P. Diversity of fungal endophytes in non-native Phragmites australis in the Great Lakes. Biol. Invasions 2016, 18, 2703-2716. [CrossRef]

19. Soares, M.A.; Li, H.; Kowalski, K.P. Evaluation of the functional roles of fungal endophytes of Phragmites australis from high saline and low saline habitats. Biol. Invasions 2016, 18, 2689-2702. [CrossRef]

20. Shipunov, A.; Newcombe, G.; Raghavendra, A.K.H.; Anderson, C.L. Hidden diversity of endophytic fungi in an invasive plant. Am. J. Bot. 2008, 95, 1096-1108. [CrossRef]

21. Allen, W.J.; Devries, A.E.; Bologna, N.J.; Bickford, W.A.; Kowalski, K.P.; Meyerson, L.A.; Cronin, J.T. Intraspecific and biogeographical variation in foliar fungal communities and pathogen damage of native and invasive Phragmites australis. Glob. Ecol. Biogeogr. 2020, 29, 1199-1211. [CrossRef]

22. Bickford, W.A.; Goldberg, D.E.; Kowalski, K.P.; Zak, D.R. Root endophytes and invasiveness: No difference between native and non-native Phragmites in the Great Lakes Region. Ecosphere 2018, 9, e02526. [CrossRef]

23. Bowen, J.L.; Kearns, P.J.; Byrnes, J.E.K.; Wigginton, S.; Allen, W.J.; Greenwood, M.; Tran, K.; Yu, J.; Cronin, J.T.; Meyerson, L.A. Lineage overwhelms environmental conditions in determining rhizosphere bacterial community structure in a cosmopolitan invasive plant. Nat. Commun. 2017, 8, 433. [CrossRef] [PubMed]

24. Nelson, E.B.; Karp, M.A. Soil pathogen communities associated with native and non-native Phragmites australis populations in freshwater wetlands. Ecol. Evol. 2013, 3, 5254-5267. [CrossRef] [PubMed] 
25. Dean, S.L.; Farrer, E.C.; Taylor, D.L.; Porras-Alfaro, A.; Suding, K.N.; Sinsabaugh, R.L. Nitrogen deposition alters plant-fungal relationships: Linking belowground dynamics to aboveground vegetation change. Mol. Ecol. 2013, 23, 1364-1378. [CrossRef] [PubMed]

26. Cesarino, I.; Ioio, R.D.; Kirschner, G.K.; Ogden, M.S.; Picard, K.L.; Rast-Somssich, M.I.; Somssich, M. Plant science's next top models. Ann. Bot. 2020, 126, 1-23. [CrossRef] [PubMed]

27. Clevering, O.A.; Lissner, J. Taxonomy, chromosome numbers, clonal diversity and population dynamics of Phragmites australis. Aquat. Bot. 1999, 64, 185-208. [CrossRef]

28. Meyerson, L.A.; Cronin, J.T.; Pyšek, P. Phragmites australis as a model organism for studying plant invasions. Biol. Invasions 2016, 18, 2421-2431. [CrossRef]

29. Achenbach, L.; Brix, H. Can differences in salinity tolerance explain the distribution of four genetically distinct lineages of Phragmites australis in the Mississippi River Delta? Hydrobiologia 2013, 737, 5-23. [CrossRef]

30. Mozdzer, T.J.; Brisson, J.; Hazelton, E.L.G. Physiological ecology and functional traits of North American native and Eurasian introduced Phragmites australis lineages. AoB Plants 2013, 5, plt048. [CrossRef]

31. Vasquez, E.; Glenn, E.; Brown, J.; Guntenspergen, G.; Nelson, S. Salt tolerance underlies the cryptic invasion of North American salt marshes by an introduced haplotype of the common reed Phragmites australis (Poaceae). Mar. Ecol. Prog. Ser. 2005, 298, 1-8. [CrossRef]

32. Fischer, M.S.; Rodriguez, R.J. Fungal endophytes of invasive Phagramites australis populations vary in species composition and fungicide susceptibility. Symbiosis 2013, 61, 55-62. [CrossRef]

33. Saltonstall, K. Cryptic invasion by a non-native genotype of the common reed, Phragmites australis, into North America. Proc. Natl. Acad. Sci. USA 2002, 99, 2445-2449. [CrossRef] [PubMed]

34. Lambertini, C.; Mendelssohn, I.A.; Gustafsson, M.H.G.; Olesen, B.; Riis, T.; Sorrell, B.K.; Brix, H. Tracing the origin of Gulf Coast Phragmites (Poaceae): A story of long-distance dispersal and hybridization. Am. J. Bot. 2012, 99, 538-551. [CrossRef]

35. Meyerson, L.A.; Lambertini, C.; McCormick, M.K.; Whigham, D.F. Hybridization of common reed in North America? The answer is blowing in the wind. AoB Plants 2012, 2012, pls 002. [CrossRef] [PubMed]

36. Meyerson, L.A.; Lambert, A.M.; Saltonstall, K. A Tale of three lineages: Expansion of common reed (Phragmites australis) in the U.S. Southwest and Gulf Coast. Invasive Plant. Sci. Manag. 2010, 3, 515-520. [CrossRef]

37. Farrer, E.C.; Birnbaum, C.; Waryszak, P.; Halbrook, S.R.; Brady, M.V.; Bumby, C.R.; Candaele, H.; Kulick, D.; Lee, S.F.H.; Schroeder, C.S.; et al. Above and belowground impacts of an invasive species vary across the landscape. J. Ecol. 2016. under review.

38. Callahan, B.J.; McMurdie, P.J.; Rosen, M.J.; Han, A.W.; Johnson, A.J.; Holmes, S. DADA2: High-resolution sample inference from Illumina amplicon data. Nat. Methods 2016, 13, 581-583. [CrossRef]

39. Nguyen, N.H.; Song, Z.; Bates, S.T.; Branco, S.; Tedersoo, L.; Menke, J.; Schilling, J.S.; Kennedy, P.G. FUNGuild: An open annotation tool for parsing fungal community datasets by ecological guild. Fungal Ecol. 2016, 20, 241-248. [CrossRef]

40. Hill, M.O. Diversity and Evenness: A Unifying Notation and Its Consequences. Ecology 1973, 54, 427-432. [CrossRef]

41. Alberdi, A.; Gilbert, M.T.P. Hilldiv: An r package for the integral analysis of diversity based on Hill numbers. bioRxiv 2019, 545665. [CrossRef]

42. Jost, L. Partitioning diversity into independent alpha and beta components. Ecology 2007, 88, 2427-2439. [CrossRef] [PubMed]

43. R Core Team. R: A Language and Environment for Statistical Computing; R Foundation for Statistical Computing: Vienna, Austria, 2017.

44. Oksanen, J.; Blanchet, F.G.; Friendly, M.; Kindt, R.; Legendre, P.; McGlinn, D.; Minchin, P.R.; O’Hara, R.B.G.; Simpson, L.; Solymos, P.; et al. Vegan: Community Ecology Package; R package Version 2.5-5; R Foundation for Statistical Computing: Vienna, Austria, 2019.

45. Pinheiro, J.; Bates, D.; DebRoy, S.; Sarkar, D.; R Core Team. Nlme: Linear and Non-Linear Mixed Effects Models; EcoLab University of Granada: Granada, Spain, 2019.

46. Zuur, A.F.; Ieno, E.N.; Walker, N.; Saveliev, A.A.; Smith, G.M. Mixed Effects Models and Extensions in Ecology with R.; Springer Science and Business Media LLC: Berlin/Heidelberg, Germany, 2009.

47. Borcard, D.; Legendre, P. All-scale spatial analysis of ecological data by means of principal coordinates of neighbour matrices. Ecol. Model. 2002, 153, 51-68. [CrossRef]

48. Wickham, H. ggplot2: Elegant Graphics for Data Analysis; Springer: New York, NY, USA, 2016. 
49. McMurdie, P.J.; Holmes, S. phyloseq: An r package for reproducible interactive analysis and graphics of microbiome census data. PLoS ONE 2013, 8, e61217. [CrossRef] [PubMed]

50. Lenth, R. emmeans: Estimated Marginal Means, aka Least-Squares Means; University of Iowa: Iowa City, IA, USA, 2020.

51. Kirk, P.M.; Cannon, P.F.; Minter, D.W.; Stalpers, J.A. Dictionary of the Fungi, 10th ed.; CAB International: Wallingford, UK, 2008.

52. Westover, K.M.; Kennedy, A.C.; Kelley, S.E. Patterns of rhizosphere microbial community structure associated with co-occurring plant species. J. Ecol. 1997, 85, 863. [CrossRef]

53. Rosenblueth, M.; Martinez-Romero, E. Bacterial endophytes and their interactions with hosts. Mol. Plant. Microbe Interact. 2006, 19, 827-837. [CrossRef]

54. Hardoim, P.R.; Van Overbeek, L.S.; Berg, G.; Pirttilä, A.M.; Compant, S.; Campisano, A.; Döring, M.; Sessitsch, A. The hidden world within plants: Ecological and evolutionary considerations for defining functioning of microbial endophytes. Microbiol. Mol. Boil. Rev. 2015, 79, 293-320. [CrossRef]

55. Micallef, S.A.; Shiaris, M.P.; Colón-Carmona, A. Influence of Arabidopsis thaliana accessions on rhizobacterial communities and natural variation in root exudates. J. Exp. Bot. 2009, 60, 1729-1742. [CrossRef]

56. Olivares, F.L.; Baldani, V.L.D.; Reis, V.M.; Baldani, J.I.; Döbereiner, J. Occurrence of the endophytic diazotrophs Herbaspirillum spp. in roots, stems and leaves predominantly of Gramineae. Biol. Fertil. Soils 1996, 21, 197-200. [CrossRef]

57. Weber, O.; Baldani, V.; Teixeira, K.; Kirchhof, G.; Baldani, J.; Döbereiner, J. Isolation and characterization of diazotrophic bacteria from banana and pineapple plants. Plant. Soil 1999, 210, 103-113. [CrossRef]

58. Si, C.; Liu, X.; Wang, C.; Wang, L.; Dai, Z.; Qi, S.; Du, D. Different degrees of plant invasion significantly affect the richness of the soil fungal community. PLoS ONE 2013, 8, e85490. [CrossRef] [PubMed]

59. Lankau, R. Resistance and recovery of soil microbial communities in the face of Allaria petiolata invasions. New Phytol. 2011, 189, 536-548. [CrossRef] [PubMed]

60. Mangla, S.; Callaway, R.M. Exotic invasive plant accumulates native soil pathogens which inhibit native plants. J. Ecol. 2007, 96, 58-67. [CrossRef]

61. Nijjer, S.; Rogers, W.E.; Siemann, E. Negative plant-soil feedbacks may limit persistence of an invasive tree due to rapid accumulation of soil pathogens. Proc. R Soc. B Boil. Sci. 2007, 274, 2621-2627. [CrossRef]

62. Chen, L.; Zhou, J.; Zeng, T.; Miao, Y.; Mei, L.; Yao, G.; Fang, K.; Dong, X.; Sha, T.; Yang, M.; et al. Quantifying the sharing of foliar fungal pathogens by the invasive plant Ageratina adenophora and its neighbours. New Phytol. 2020, 227, 1493-1504. [CrossRef]

63. Diez, J.M.; Dickie, I.; Edwards, G.R.; Hulme, P.E.; Sullivan, J.J.; Duncan, R.P. Negative soil feedbacks accumulate over time for non-native plant species. Ecol. Lett. 2010, 13, 803-809. [CrossRef]

64. Flory, S.L.; Clay, K. Pathogen accumulation and long-term dynamics of plant invasions. J. Ecol. 2013, 101, 607-613. [CrossRef]

65. Elton, C.S. The Ecology of Invasions by Animals and Plants; Springer Science and Business Media LLC: Berlin/Heidelberg, Germany, 1958.

66. Levine, J.; Pachepsky, E.; Kendall, B.E.; Yelenik, S.; Lambers, J.H.R. Plant-soil feedbacks and invasive spread. Ecol. Lett. 2006, 9, 1005-1014. [CrossRef]

67. Devries, A.E.; Kowalski, K.P.; Bickford, W.A. Growth and behavior of North American microbes on Phragmites australis leaves. Microorganisms 2020, 8, 690. [CrossRef]

68. Allen, W.J.; Meyerson, L.A.; Flick, A.J.; Cronin, J.T. Intraspecific variation in indirect plant-soil feedbacks influences a wetland plant invasion. Ecology 2018, 99, 1430-1440. [CrossRef]

69. Castrillo, G.; Teixeira, P.J.P.L.; Paredes, S.H.; Law, T.F.; De Lorenzo, L.; Feltcher, M.E.; Finkel, O.M.; Breakfield, N.W.; Mieczkowski, P.A.; Jones, C.D.; et al. Root microbiota drive direct integration of phosphate stress and immunity. Nature 2017, 543, 513-518. [CrossRef] [PubMed]

70. Hacquard, S.; Garrido-Oter, R.; González, A.; Spaepen, S.; Ackermann, G.; Lebeis, S.; McHardy, A.C.; Dangl, J.L.; Knight, R.; Ley, R.; et al. Microbiota and host nutrition across plant and animal kingdoms. Cell Host Microbe 2015, 17, 603-616. [CrossRef] [PubMed]

71. Power, A.G.; Mitchell, C.E. Pathogen spillover in disease epidemics. Am. Nat. 2004, 164, S79-S89. [CrossRef] [PubMed]

72. Bonsall, M.B.; Hassell, M.P. Apparent competition structures ecological assemblages. Nature 1997, 388, 371-373. [CrossRef] 
73. Lekberg, Y.; Vasar, M.; Bullington, L.S.; Sepp, S.; Antunes, P.M.; Bunn, R.A.; Larkin, B.G.; Öpik, M. More bang for the buck? Can arbuscular mycorrhizal fungal communities be characterized adequately alongside other fungi using general fungal primers? New Phytol. 2018, 220, 971-976. [CrossRef]

74. Redman, R.S.; Dunigan, D.D.; Rodriguez, R. Fungal symbiosis from mutualism to parasitism: Who controls the outcome, host or invader? New Phytol. 2001, 151, 705-716. [CrossRef]

(C) 2020 by the authors. Licensee MDPI, Basel, Switzerland. This article is an open access article distributed under the terms and conditions of the Creative Commons Attribution (CC BY) license (http://creativecommons.org/licenses/by/4.0/). 